\section{Odds and ends about the dead and buried}

\section{Stuart Piggott}

Rites of the Gods. By Aubrey Burl. Pp. 258. ISBN 0-460-04313-7. (Dent: 1981.) £12.

WITH its meretricious title and dust-jacket, is Mr Burl's book going to lead us to take the "misdirected step" that "leads one towards apparitions, White Goddesses, psychic archaeology and the Never-Never land of the ley-liners"'? Of course not: the deservedly caustic phrases are those of the author. But his book is not quite what it might seem to be, for it is not a discussion of ancient non-Christian cults, not even of those inferred for prehistoric Europe, but is limited in space to the British Isles and in time to a period c. $4500-1000 \mathrm{BC}$, with sketchy chapters for the phases before and after. Within these limitations $\mathrm{Mr}$ Burl presents to the non-archaeological reader some of the inferences which can be made as to ritual practice and performance from the material culture of burial and ceremonial monuments, a field to which he has made important contributions.

In the six chapters which form the bulk of the book the treatment is not thematic but topographical, with what seems a capriciously selected series of field monuments, some surviving, some destroyed or invisible from the ground. This does not make for easy or even very interesting reading, and obscures the real topics which could have been explored, such as the variations perceptible in the rites of collective burial - successive, redeposited, partial or complete - or a fuller treatment of the claims for astronomical the author has made pertinent comments elsewhere that deserve re-statement. Unfortunately, too, there are many errors of detail in the site descriptions, and the reports of early antiquarian diggings are sometimes given more credence in detail than they deserve. Modern "folklore" is also dealt with uncritically and without regard to the absorption by popular tradition, from the Renaissance onwards, of literate antiquarian speculations. Even less sure is the handling of anthropological evidence, where a sprinkling of words such as "shaman", "totem", "mana" or "sympathetic magic" hardly inspires confidence, and Ucko's classic paper of 1969 (World Archaeology I.2, 262-280) on precisely the problems posed by the interpretation of prehistoric funerary practice is not mentioned, though it should be required reading for all concerned. The limitations of inference from "grave archaeology"' are nowhere set out.

Surprisingly, when in the later first millennium BC something, however tenuous, becomes explicit in Celtic religion, the book tails away. Here it is strange, in view of the prominence rightly given to henge monuments and allied structures earlier in the book, that nothing expertise in British prehistory, on which is said of the evidence discussed in several recent papers for an insular survival of this pre-Celtic sanctuary tradition in such sites as Dun Ailinne or Emain Macha (and Tara), with probable British counterparts; the circular timber Iron Age temple beneath the Roman structure on Hayling Island is among other new and important cult sites of the period.
All in all, Rites of the Gods cannot be called a success, and does little more than present the reader with a scrap-book of miscellaneous data, too often interpreted in terms of modern modes of thinking. I had expected, and the general public deserves, something much better from $\mathrm{Mr}$ Burl.

Stuart Piggott retired as Abercromby Professor in 1977. His books include Ancient Europe (Edinburgh University Press, 1965) and The Druids (Thames \& Hudson/Pelican, 1974). of Archaeology at the University of Edinburgh

\section{Jupiter and the Moon displayed}

\section{David W. Hughes}

I FIND map books fascinating and spend many happy hours investigating a specific country and tracing the lines of equal height, geological structure, nationality, temperature, rainfall, population, magnetic inclination and so on. The fascination seems to be a function of the amount of information displayed, so turning to the planets the first question is, "Do we know enough to fill a good atlas?". Looking at the two atlases under review one also must ask if all the relevant information has been included.

The first two volumes in The Mitchell Beazley Library of Astronomical Atlases for Amateur and Professional Observers deal with Jupiter and the Moon. Jupiter has been written by Garry Hunt and Patrick Moore, who divide their attention equally between the planet and its satellites. There is no doubt about there being enough knowledge to fill an atlas here. The images from Voyager 1 and 2 and Pioneer 10 and 11 , apart from revealing three new satellites and a ring around the planet, have provided a host of superb pictures. This atlas reproduces many of these in colour. It not only provides maps of Jupiter and its satellites, but it also reviews our knowledge of such topics as The Great Red Spot, the interior of Jupiter, the magnetosphere, the effect of Io on Jovian radio emission, cloud morphology and colouring, volcanism on
Io, surface fracturing on Europa, and cratering on Callisto and Ganymede.

The book is well written, physical and astronomical terms being clearly and correctly defined.

After the excitement of the Pioneer and Voyager fly-bys we are now scientifically becalmed and must return to "oldfashioned" visual and photographic observations from Earth. No Earth-based telescope can show anything like the amount of detail provided by space imaging, but Jupiter can be kept under observation for a large fraction of each year. It is thus well worth mentioning that the bible of Jupiter watchers - Bertrand M. Peek's The Planet Jupiter, The Observer's Handbook - has been reissued in a revised edition (Faber and Faber; $£ 10, \$ 29.95$ ). Needless to say, with 170 pages devoted to observations of the belts and zones of Jupiter and their temporal variation, this book is not for the faint hearted.

The second atlas, The Moon by Patrick Moore, reflects, to quote the author, "the endless enjoyment to be gained simply from looking at the Moon'". Despite being visited by astronauts and a multitude of unmanned probes, the Moon has lost nothing of its romance. Again, the atlas contains about 16 pages of colour plates and a large collection of stereographic, orthographic and Mercator maps of lunar regions.

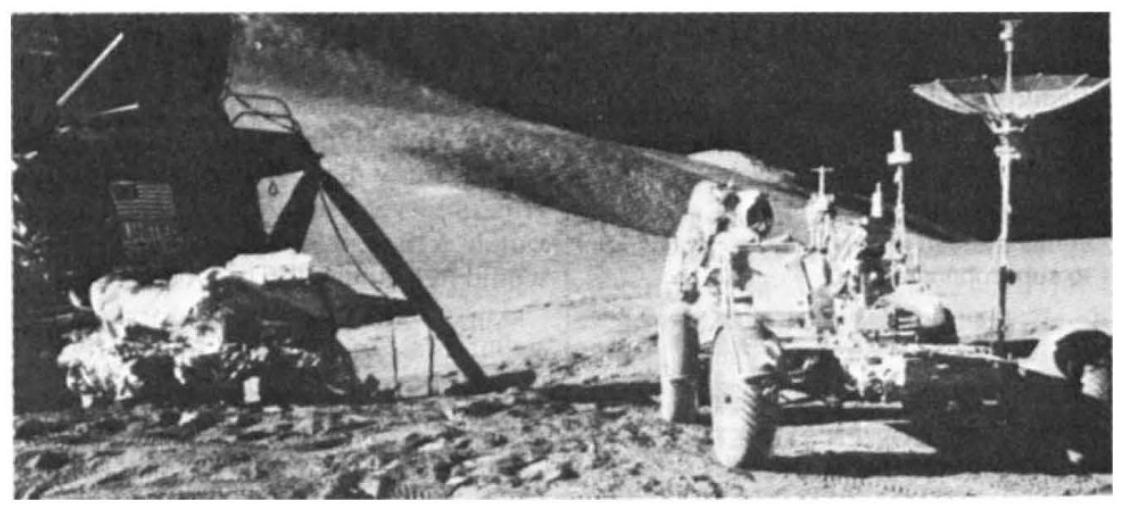

The mobile man in the Moon - James B. Irwin and the Lunar Roving Vehicle. The picture is taken from Joseph Jackson and John Baumert's Pictorial Guide to the Planets, 3rd Edn, just published by Harper \& Row, price $£ 9.50$ 